\title{
Physical activity level as a booster of entrepreneurial intention: a social innovation approach
}

Check for updates

\section{Ricardo Rodrigues ${ }^{1,2}$ (D) Carla Susana Marques ${ }^{3}$. Dulce Esteves ${ }^{1,4}$ - Rui Brás ${ }^{1,4}$. Gina Santos $^{3}$ - Ana Gouveia ${ }^{1,5} \cdot$ Paulo Duarte $^{1,2} \cdot$ Paulo Pinheiro $^{1,2}$. Kelly $\mathrm{O}^{\prime} \mathrm{Hara}^{1} \cdot$ Vanessa Marques $^{3}$}

Received: 16 May 2019 / Accepted: 31 July 2019/Published online: 10 August 2019

(C) Springer-Verlag GmbH Germany, part of Springer Nature 2019

\begin{abstract}
This study aims to investigate if engaging in physical activity (PA) and gender influences people's entrepreneurial intention (EI). A survey for measuring EI and PA was developed and administered to the general population. The data were collected with a questionnaire distributed across all continental Portuguese regions. A two-way analysis of variance was used to test the influence of PA level and gender in EI. The results highlight that PA and gender have an impact on EI. This study's main practical implication is that evidence was found that people need to be involved in more PA, especially in high PA level, because the results show that there is an association with increased levels of EI. This paper contributes to filling a gap in the literature by identifying the importance of PA for the increase of EI. This relationship may be a consequence of skills promoted by the practice of PA and also the development of some personal psychological and cognitive characteristics such as autonomy, risk tolerance, and leadership. The main implication resulting from this study is that it is essential to develop and booster PA into society, namely through PA programmes in organisations, not only for improving persons' health condition but also as a social benefit, that can promote social innovation and entrepreneurship.
\end{abstract}

Keywords Entrepreneurial intention $\cdot$ Physicalactivity $\cdot$ Social innovation $\cdot$ Sports $\cdot$ Gender

\section{Introduction}

Entrepreneurship is broadly recognized as a vehicle for national and regional development (Galvão et al. 2017; Galvão et al. 2019) since it increases economic efficiencies, produces innovation, jobs, growth over time (González-Serrano et al. 2018), and

Ricardo Rodrigues

rgrodrigues@ubi.pt

Extended author information available on the last page of the article 
national prosperity (Bell 2019). Thus, entrepreneurs boost competitiveness and wealth creation. Particularly entrepreneurial graduate students are vital for the development of entrepreneurial activities, besides an increasing number of graduates are not employed in the sector they studied (Fragoso et al. 2019), entrepreneurship can be considered as a solution, and entrepreneurial intention and psychological and cognitive entrepreneur's profile can be increased through education or practical activities (PA) (Marques et al. 2012). Consequently, entrepreneurship captured the interest of both scholar and policymakers (Alferaih 2017). Regarding policymakers, they find it the solution for social and economic problems (González-Serrano et al. 2018).

Social innovation has gained importance over time and is considered by several authors as new, more effective and sustainable responses to the new societal challenges of the twenty-first century. In this way, it promotes structural changes in the improvement of well-being and quality of life, to generate new forms of social change through the empowerment of citizens and reorganization of civil society, including organizations, to meet social and human needs, creating social value (e.g., Marques et al. 2018; Pol and Ville 2009). According to Dawson and Daniel (2010b), social innovation plays a vital role in improving the well-being of people, communities, and society. It is driven by social change and the definition of collective strategies through social entrepreneurship, reconciling business strategies with social objectives.

However, to date, there is no standard definition of entrepreneurship (Westhead and Wright 2013), and it has become a buzzword. Entrepreneurship is recognised as a multidimensional and complex phenomenon with several angles explored in the literature, resulting in different definitions (Landström 2008). Nonetheless, according to Marques et al. (2011a), all entrepreneurs can be identified through common psychological and cognitive characteristics, being autonomy, self-esteem, tolerance to risk, and organisational and leadership skills examples of these characteristics. However, according to the literature, we can all be entrepreneurs; we need to be and develop the skills to do so (Ferreira et al. 2010). Even though the existence of some individual characteristics can act as facilitators for entrepreneurial activity, entrepreneurship can be taught and developed (Ferreira et al. 2010).

Although the existence of decades of investigations, scholars possess only limited comprehension about what leads to becoming an entrepreneur (Zhao et al. 2005), being undeniable the importance of understanding the factors and decision-making process that influence an individual to start-up to stimulate it (Díaz-García and Jiménez-Moreno 2010). Therefore, entrepreneurial intentions (EI) influence and are vital for the entrepreneurial field (Chia and Liang 2016). EI remains the best predictor of entrepreneurial behaviour (Liñán et al. 2016) and, consequently, EI is a rapidly evolving field of research. A growing number of studies use EI as a robust theoretical framework (Liñán and Fayolle 2015).

PA is linked to different benefits, such as stress reduction, increase in work performance (e.g., Brinkley et al. 2017) and teamwork/social competencies (e.g., Holt et al. 2011). In the context of entrepreneurship, Marques et al. (2011a) argued that engaging in yoga enhances psychological and cognitive attributes commonly linked to entrepreneurial profile. Nonetheless, there is a gap in the literature concerning investigations about the link between the engagement in PA and EI, once there are limited studies (e.g., Naia et al. 2017; Marques et al. 2011a) and more research would be useful. 
Many studies evidence a lower amount of female EI compared with men (e.g., Fragoso et al. 2019; Wilson et al. 2007; Zhao et al. 2005) as well as that men, compared to women, consider entrepreneurship more attractive than other jobs (e.g., Díaz-García and Jiménez-Moreno 2010; Ahl 2006). Consequently, it is fundamental to identify the factors responsible for this reality (LópezDelgado et al. 2019).

We respond to the call by Fayolle and Liñán (2014) for further investigations on EI, and to our knowledge, no empirical study examined the single and combined effect of engaging in PA and gender on EI.

This research aims to investigate if engaging in physical activity (PA) or gender influences sports practitioner's IE, using a quantitative methodology. Consequently, the following research questions are proposed: Does PA impact on the EI of these individuals? Moreover, can this can vary according to gender?

This paper contributes to the literature by identifying PA as an antecedent of entrepreneurship. Its results can be used by policymakers to promote PA not only to improving health care but also as a booster to entrepreneurial intentions, as to say to strengthen self-employment. Policies can support entrepreneurship in many ways, yet it is crucial to investigate which factors influence and shape individuals' intent to become an entrepreneur to be able to develop adequate programmes and policies (GonzálezSerrano et al. 2018). Higher education institutions have a crucial role in promoting PA programmes that can help booster entrepreneurship and intrapreneurship intention. These organisations have the most vital role in this practical implication because they encourage not only IE through entrepreneurship education programmes but also through PA programmes that can help to develop some desired entrepreneurial skills like leadership and social skills that later could be into the organisations where these students become professionals.

The remainder of this paper is organised as follows. The next section presents a review of the literature. Section 3 provides the methodological background, while Section 4 discusses the results obtained. The last section offers the study's contributions, limitations and a roadmap for future research.

\section{Literature review}

\subsection{Entrepreneurial intention (EI)}

Prior studies have applied a variety of theoretical frameworks, models and theories (Alferaih 2017) to expand knowledge of EI and explain why some people have more propension to entrepreneurship. Since there is general agreement in the literature about the role that intentions play in the decision to become an entrepreneur (e.g., Fragoso et al. 2019) and, therefore, to predict entrepreneurial behaviour (Liñán and Chen 2009). The decision to start-up is regarded as deliberate and conscious, besides entrepreneurship is considered as a process happening over time (Liñán and Chen 2009), is the formation of the intention the first step in this process across various theories (Fragoso et al. 2019). Based on Alferaih (2017), we define EI as the intention of a person to start a new business where "intentions are assumed to capture the motivational factors that influence a behaviour” (Ajzen 1991, p. 181). 
According to Fayolle and Liñán (2014) the development of EI has been guided principally by three conceptual models: (1) Bird's (1988) model, (2) Shapero and Sokol's (1982) model and (3) Ajzen's (1991) theory of planned behaviour (TPB). Bird (1988) was one of the first researchers in the field of (Carsrud and Brännback 2009). However, her model still needs to be validated empirically (Fayolle and Liñán 2014). Thus, Shapero and Sokol's (1982) entrepreneurial event model (EEM), and TPB have received predominant attention (Schlaegel and Koenig 2014) and turned to be the leading research models to study the determinants of EI (Alferaih 2017), despite TPB being developed to explain individual planned behaviour in general (Carsrud and Brännback 2009; Shook et al. 2003) and afterwards adapted by entrepreneurship researchers (Schlaegel and Koenig 2014).

In agreement with Shapero and Sokol's (1982) model, EI is influenced by individual's perception of feasibility and desirability, and the propensity to act (Carsrud and Brännback 2009; Guerrero et al. 2008; Shook et al. 2003). Perceived desirability reflects personal attractiveness of becoming an entrepreneur, including both intrapersonal and extrapersonal impacts. Perceived feasibility is the degree to which individuals are confident that they can become an entrepreneur (Krueger et al. 2000). Finally, the propensity to act upon opportunities is the disposition of an individual to work on one's decision (Schlaegel and Koenig 2014). Consequently, "positive attitudes toward entrepreneurship will positively affect the personal attractiveness of starting one's own business as more favourable attitudes justify more favourable perceptions of desirability of the behaviours related to the goal of becoming an entrepreneur" (Schlaegel and Koenig 2014, p. 300).

Concerning TPB, it is considered the most influential and rigorous model to explain EI (López-Delgado et al. 2019; Liñán et al. 2016). Indeed, the TPB considers personal history, characteristics, and skills as well as social factors (Rueda et al. 2015). Ajzen (1991) argues that three motivational factors shape individual intention to pursue a behaviour (Shook et al. 2003). Jointly, these motivational factors lead to the development of behaviour intention (Ajzen and Fishbein 2000). Namely (1) the attitude towards the act, which is defined as individual's appraisal, favourable or unfavourable, to a behaviour in question; (2) the subjective norms (SN) describe individual's perceived social pressure to involve (or not to involve) in particular entrepreneurial behaviour; and (3) the perceived control over the behaviour (PBC) concerns individual's perception of the ease or difficulty of carrying out a specific behaviour and should reflect experience along with anticipation of barriers that may occur in the future (Ajzen 1991). Thus, the more positive the attitude and SN regarding specific behaviour and the better the PBC, the stronger the intention to carry out this behaviour should be (Autio et al. 2001). The principal tenet of the TPB is that any behaviour demands a certain amount of planning and thus can be predicted by intentions to adopt that behaviour (Alferaih 2017) and in the matter of remaining factors, they affect intentions indirectly, through these three antecedents (Rueda et al. 2015). Consequently, according to this theory and in the entrepreneurial context, EI can be defined as the individual's effort to accomplish an entrepreneurial behaviour, besides intentions can be affected directly by motivational antecedents (e.g., SN) and indirectly by situational factors (e.g., time constraints), by human capital and other demographic aspects (Naia et al. 2017).

Both revered models have common elements since the desired perception, referring to value system of an individual of the EEM, is portrayed by two aspects of the TPB, 
namely (1) the attitude towards the act, and (2) SN (Díaz-Casero et al. 2012). Notwithstanding, the principal difference between the two models is that TPB stresses the role of SN more than does the MEE, which emphasises characteristics and past entrepreneurial experience of the person (Autio et al. 2001).

Nonetheless, it is noteworthy to highlight that Douglas (2013) uncovers differences in the intentions that lead an individual to start a business accordingly to what he pursues, that is, the individual can seek for professional grow or go after more independence.

\subsection{Entrepreneurial intention and gender}

Regarding the TPB, gender is thought to affect intentions in so far as personality traits influence the individuals' beliefs to start a business (Badri and Hachicha 2019). Notably, women, compared to men, tend to present lower entrepreneurial attitudes, Perceived Behavioural Control and Subjective Norms (Fragoso et al. 2019). Thornton, Ribeiro-Soriano, and Urbano (2011, p. 106) claimed the importance of implicit norms, social mores and socio-cultural aspect on EI, "arguing that entrepreneurship is embedded in a social context". Moreover, concerning women, they are highly influenced by societal norms and careers ascribed to them (Díaz-García and Jiménez-Moreno 2010). For example, engineering, surgery, and judiciary jobs are, regarding stereotypes, men's work while nursing and secretarial jobs are women's work (Gupta et al. 2009). The existing literature shows that stereotypes associate typical qualities of entrepreneurship to a greater extent to the personality socially assigned to men (López-Delgado et al. 2019). Thus, it is crucial to highlighting that EI is influenced how gender and entrepreneurship are socially established (Gupta et al. 2009).

Women, compared with men, acknowledge themselves as less capable of starting a business and noticed their environment as requiring more effort and less suitable for business start-up (Gupta et al. 2009). In agreement with Shinnar, Giacomin, and Janssen (2012, p. 473), intentions are affected by perceived appropriateness and ability to perform specific behaviour, therefore, "if entrepreneurship is not considered to be a desirable or appropriate career for women in a certain culture, even women who feel that barriers are relatively unimportant may choose not to pursue it". This conclusion is consistent with Wilson et al. (2007) that suggest that women are more probable than men to limit their career aspirations because they think they have not the necessary skills. Ergo, women are expected to have lower EI as compared with men (Gupta et al. 2009).

As a matter of fact, there is substantial consensus in the literature of lower amount of female EI compared with men (e.g., Fragoso et al. 2019; Wilson et al. 2007; Zhao et al. 2005), even on teens, the expected next generation of entrepreneurs, girls, show less EI (e.g., Wilson et al. 2007). Although female entrepreneurship is growing increasing rapidly and plays an important role (Wilson et al. 2007), female entrepreneurs still represent only half of the male entrepreneurs (Shinnar et al. 2012) and this reality is consistent across different nations (Gupta et al. 2009). Besides many studies evidenced that men, compared to women, acknowledge entrepreneurship more attractive than other professions (e.g., Díaz-García and Jiménez-Moreno 2010; Ahl 2006) and women are driven to entrepreneurship with the desire to better adjust work and family life (Brush et al. 2014; Marques et al. 2011b). Thus, it is imperative to identify factors responsible for this reality (López-Delgado et al. 2019). 
One reason for these results can lay on that entrepreneur is a masculine concept and individuals (both men and women) characterise entrepreneurship as a male career (Gupta et al. 2009; Ahl 2006). Thus, it is not gender-neutral (Ahl 2006), and the majority of entrepreneurs are indeed men (Zhao et al. 2005).

\subsection{Physical activity level}

PA is characterised as a robust phenomenon with social, economic, cultural and educational fields (Naia et al. 2017), besides one of the most diffused social activities in Europe (González-Serrano et al. 2018). Furthermore, it turned out to be a social phenomenon with implications on performance, education and social intervention (González-Serrano et al. 2018), mainly through practising sport. Young people gain specific personal and professional attributes capable of improving employment (Vassiliou 2014).

For the pursuit of this research, sports is defined as "all forms of PA which, through casual or organised participation, aim at expressing or improving physical fitness and mental well-being, forming social relationships or obtaining results in competition at all levels" (Council of Europe 1992).

There are extensive knowledge and research on the benefits of engagement in PA. For example, regarding team sports, Brinkley et al. (2017) argued that it holds advantages for the individual (e.g., health, reduced stress and tension, well-being), for group (e.g., improved teamwork relations, team trust, and communication) and for organisational health (e.g., sickness absence; increase in work performance). Likewise, the engagement in PA by children is linked with social benefits (e.g., making new friends, and teamwork/social competencies) and personal benefits (e.g., emotional control, confidence, and academic performance) (Holt et al. 2011). In terms of outdoor sport, beyond health benefits, it is also linked to intra and interpersonal improvement of young people (Eigenschenk et al. 2019).

Specifically applied to the field of entrepreneurship and PA there is a study by Marques et al. (2011a, p. 255), whose results indicate "that students who do engage in yoga show a propensity towards or strengthening of the psychological and cognitive attributes that are commonly associated with an entrepreneurial profile". Consequently, if EI is to be stimulated, then yoga should be part of general education from primary school onwards (Marques et al. 2011a).

In summary, previous studies analysing EI have been applied within a different context, although a lack of studies investigating the link between EI and engagement in PA exists as the list of such studies is scarce (e.g., Naia et al. 2017; Marques et al. 2011a) and therefore, more research is needed.

\subsection{Social innovation}

Social innovation stands for innovative activities or services that are driven by a social need (Mulgan 2006), triggered by a concern in improving the well-being of people in society (Dawson and Daniel 2010a, b). According to Cajaiba-Santana (2014), social innovation is a driver for desired social change, and it occurs in a complex context (Rao-Nicholson et al. 2017).

The interest in social innovation by the scientific community has been growing, as unveiled by the systematic review conducted by Eichler and Schwarz (2019). 
Nonetheless, these authors' results led them to conclude that research in social innovation is still in its infancy. For instance, research linking social innovation and entrepreneurship is only very recent and is intertwined with other research traditions (van der Have and Rubalcaba 2016). But the interest in this linkage has been growing in the past years as shown by Phillips et al. (2015).

One salient aspect of the research in the interface between social innovation and entrepreneurship is the importance of the needs of the target beneficiaries of social innovation. Lubberink et al. (2019) conclude that social entrepreneurs focus on creating value for their target beneficiaries. For Onsongo (2019), appealing to the needs of target users is required for legitimating social innovations.

The centrality of the end-user is also noticeable in social innovations designed to increase PA. Aligned with this view on the centrality of the end-user, Metsios and Kitas (2018) advocate for the implementation of social innovations that adopt PA programmes for patients with specific pathologies, like rheumatoid arthritis. A realworld example is given by Grindell et al. (2019), who explore the acceptability and usability of iStep, a social innovation to encourage intergenerational physical activity, concluding that it has the potential to foster increased PA across generations. Jones et al. (2019) noticed that social innovation to promote PA tends to focus on formal programmes, like sports activities. They conclude that sports activities are not more associated with higher levels of PA than other forms of physically active leisure.

\section{Methods}

This investigation is based on a cross-sectional population-based study in Portugal. A total of 1310 participants aged between 15 and 92 years old (mean $=42.1 ; \mathrm{SD}=19.6$ ), $54 \%$ male, were included in this study. Individuals were asked to answer several questions regarding their PA level and EI. Participants were recruited in public places, in different across all regions of Portugal, in cities and rural villages. Participants were completely free to participate in the study, after the presentation of researchers' affiliation, investigation goals, and confidentiality assurance.

In this study, EI was defined as a purpose towards starting a new business (Kruegeret al. 2000) and was measured with a scale developed by Liñán and Chen (2009). This scale consisted of six items in Likert format.

PA level was assessed using the Portuguese validated version International Physical Activity Questionnaire short form (IPAQ, Craig et al. 2003), which estimates PA across a comprehensive set of factors to yield a score in metabolic equivalents (METS)-minutes.

All items were reviewed by an expert panel of professors and researchers not involved in the study to ensure content and face validity. The board consisted of two sports scientists (with research experience), one expert researcher on market studies and survey development and one expert researcher on knowledge management. Fieldwork supervisors conducted a pre-test of the questionnaire with a sample of 25 individuals to ensure clarity and completion time. Final data was were collected by nine researchers (post-graduate students) after attending a $10 \mathrm{~h}$ training course. We used a two-way analysis of variance (ANOVA) to test the influence of two 
independent nominal variables, PA level, and gender, in a dependent metric variable (Fisher 1950; Brandt 1931; Yates 1934), EI. This technique allows testing for the main effect of each independent variable and the interaction effect between gender and PA level.

\section{Results and discussion}

\subsection{Descriptive statistics}

Table 1 presents the mean, standard deviation, distribution, and the correlation between age and EI. The two variables are negatively, but weakly correlated (-.31). EI shows a negative mean, below the neutral value of 3 in a Likert scale (Likert 1932), and a moderate dispersion as shown by the standard deviation, the histogram, and the percentiles.

Results presented in Table 2 show that in the sample men, participants with high PA level, and single participants are the categories with the highest mean.

\subsection{Results of the comparison among groups}

A comparison of the mean EI among different levels of PA and gender was tested with a two-way ANOVA. Levene (1960) tests were computed to check homogeneity of variances in the groups formed by the different levels of gender $(\mathrm{F}(1)=.62, p=.43)$ and PA level $(\mathrm{F}(2)=.01, p=.99)$. Results show that variances are homogeneous.

With the results of a type III ANOVA, it is possible to conclude that PA level has a significant effect on EI $\left(\mathrm{F}(2)=7.302 ; p=.000 ; \eta^{2}=.011 ; \pi=.105\right)$, as well as gender $\left(\mathrm{F}(1)=8.735 ; p=.003 ; \eta^{2}=.007 ; \pi=.081\right)$, but not the interaction between the two variables $\left(\mathrm{F}(2)=.24 ; p=.784 ; \eta^{2}<.000 ; \pi=.019\right)$. Furthermore, the effect of PA level in EI is not the same for different levels of gender and PA level, as shown in Tukey HSD multiple comparisons (Tukey 1949) in Table 3. Men with high PA level present significantly higher EI means that all the women and men with low PA level.

Tellingly, only high PA level males present differences concerning the effect on EI. These differences were more notorious when compared with female gender with the most considerable difference between the low PA level females $(-0.46$; $p<0.05$ ), although it is also possible to verify the existence of a significant difference with moderate PA level females $(-0.36 ; p<0.05)$ and even with high PA level females $(-0.23 ; p<0.05)$. It should also be noted that there is a significant difference in the male gender between the elements with low and high PA levels, with low PA levels males showing a smaller effect on EI relatively to high-level PA males $(-0.34 ; p<0.05)$.

Table 1 Descriptive statistics, percentiles and correlation

\begin{tabular}{lcccccccccc}
\hline \multicolumn{1}{c}{ Variable } & N & Mean & sd & p0 & p25 & p50 & p75 & p100 & Histogram & Age \\
\hline Age & 1310 & 42.12 & 19.6 & 15 & 24 & 40 & 60 & 92 & _-_- \\
\hline Entrepreneurial intention & 1310 & 2.36 & 1.02 & 1 & 1.5 & 2.33 & 3 & 5 & $Z_{-}$ & -.31 \\
\hline
\end{tabular}


Table 2 Sample description

\begin{tabular}{llll}
\hline Variable & Frequency & Percentage & EI \\
\hline Gender & & & $2.23(1.00)$ \\
$\quad$ Female & 598 & $46 \%$ & $2.47(1.02)$ \\
$\quad$ Male & 712 & $54 \%$ & $2.13(1.03)$ \\
Physical Activity Level & & & $2.30(1.02)$ \\
$\quad$ Low & 243 & $19 \%$ & $2.46(1.01)$ \\
$\quad$ Moderate & 338 & $26 \%$ & $2.60(.99)$ \\
$\quad$ High & 729 & $55 \%$ & $2.21(1.02)$ \\
Institution type & & & $2.35(1.14)$ \\
$\quad$ Single & 583 & $45 \%$ & $1.83(.77)$ \\
$\quad$ Married or non-marital partnership & 576 & $44 \%$ & $4 \%$ \\
$\quad$ Divorced & 49 & $8 \%$ & \\
$\quad$ Widowed & 101 & & \\
\hline
\end{tabular}

Standard deviations in parenthesis. EI = Entrepreneurial Intention

\section{Conclusions and recommendations}

Based on the current study's results, it can be concluded that the practice of physical activity can boost the entrepreneurial intention. In this way, social innovation and entrepreneurship can be promoted through the availability of PA programmes developed in private and public organisations, especially in HEI.

The results also suggest that women have lower EI compared with men, which is consistent with the literature reviewed (e.g., Fragoso et al. 2019; Wilson et al. 2007; Zhao et al. 2005). It is also important to note that man with a high PA present high levels of EI, maybe through the development of some personal psychological and

Table 3 Group Means' differences and Tukey HSD post hoc tests

\begin{tabular}{|c|c|c|c|c|c|c|c|}
\hline \multirow[t]{2}{*}{ Gender } & \multirow[t]{2}{*}{ PA Level } & \multicolumn{3}{|c|}{ Female [2.23] } & \multicolumn{3}{|l|}{ Male [2.47] } \\
\hline & & Low [2.08] & Moderate [2.19] & High [2.32] & Low [2.21] & Moderate [2.40] & High [2.54] \\
\hline \multirow[t]{3}{*}{ Female } & Low & & & & & & \\
\hline & Moderate & -0.10 & & & & & \\
\hline & High & -0.23 & -0.13 & & & & \\
\hline \multirow[t]{3}{*}{ Male } & Low & -0.12 & -0.02 & 0.11 & & & \\
\hline & Moderate & -0.31 & -0.21 & -0.08 & -0.19 & & \\
\hline & High & $-0.46^{* * *}$ & $-0.36^{* *}$ & $-0.23^{*}$ & $-0.34^{*}$ & -0.15 & \\
\hline
\end{tabular}

Values in the table cells are the difference between the column mean, and the row mean of Entrepreneurial Intention. Significance of Tukey HSD: $* p<.05 ; * * p<.01 ; * * * p<.001$. Values in brackets are the group means 
cognitive characteristics such as autonomy, risk tolerance, and leadership skills that are connected to the entrepreneur profile.

It should be noted that the practice of a physical activity is not only important for health care but also beneficial for the individual as a social being. Thus, as a social factor, it promotes interactions between individuals, encouraging networks and future partnerships. In this sense and taking into account that the current investigation covered different age groups, it can be concluded that it becomes urgent to develop socially innovative programmes for sports practice, extended to all social strata. Considering the least favoured segments of society with weak economic resources, they can be promoted by all educational degrees. Mainly by HEI that consider, in the future, the implementation of social innovation programmes related to PA.

One limitation of the study relies on the fact that is based on a nonrandom sample where participants were recruited in public places, existing no selection criteria besides the engagement in PA.

Given this limitation, future research could contribute to the existing literature by expanding the findings of the studies on this topic in different ways. The first suggestion is to conduct studies comparing groups with different levels of PA in gyms, football clubs, basketball clubs, swim clubs, among others. Another future idea for future research is to investigate reasons behind the lower EI of women compared with men and why men, compared to women, recognise entrepreneurship more attractive than other professions, once we know that positive attitude toward entrepreneurship has a positive effect on becoming an entrepreneur.

We also suggest the study of university students because entrepreneurial graduate students are vital for the development of entrepreneurial activities, Moreover, since an increasing number of graduates have jobs in an area that are not directly related to their academic training they can consider entrepreneurship as an attractive solution.

Regarding these results, the main implication is that it is essential to develop and booster PA into society, namely through PA programmes in organisations, not only for a health condition but also as a social benefit, that can promote social innovation and entrepreneurship.

Acknowledgements This work is supported by public funds, through the FCT - Portuguese Foundation for Science and Technology under the projects POCI/DES/58872/2004, UID/GES/04630/2019 and UID/SOC/ $04011 / 2019$.

\section{References}

Ahl, H. (2006). Why research on women entrepreneurs needs new directions. Entrepreneurship Theory and Practice, 30(5), 595-621.

Ajzen, I. (1991). The theory of planned behavior. Organizational Behavior and Human Decision Processes, 50, 179-211.

Ajzen, I., \& Fishbein, M. (2000). Attitudes and the attitude-behavior relation: reasoned and automatic processes. European Review of Social Psychology, 11(1), 1-33.

Alferaih, A. (2017). Weight-and meta-analysis of empirical literature on entrepreneurship: towards a conceptualization of entrepreneurial intention and behaviour. The International Journal of Entrepreneurship and Innovation, 18(3), 195-209. 
Autio, E., Keeley, H. R., Klofsten, M., Parker, G. G. C., \& Hay, M. (2001). Entrepreneurial intent among students in Scandinavia and in the USA. Enterprise and Innovation Management Studies, 2(2), 145-160.

Badri, R., \& Hachicha, N. (2019). Entrepreneurship education and its impact on students' intention to start up: A sample case study of students from two Tunisian universities. The International Journal of Management Education, 17(2), 182-190.

Bell, R. (2019). Predicting entrepreneurial intention across the university. Education+ Training. https://doi. org/10.1108/ET-05-2018-0117.

Bird, B. (1988). Implementing entrepreneurial ideas: The case for intention. Academy of Management Review, 13(3), 442-453.

Brandt, A. E. (1931). The analysis of variance in a " $2 \times \mathrm{s}$ " table with disproportionate frequencies. Journal of the American Statistical Association, 28(182), 164-173.

Brinkley, A., McDermott, H., \& Munir, F. (2017). What benefits does team sport hold for the workplace? A systematic review. Journal of Sports Sciences, 35(2), 136-148.

Brush, C. G., de Bruin, A., \& Welter, F. (2014). Advancing theory development in venture creation: Signposts for understanding gender. In Women's entrepreneurship in the 21st century: an international multi-level research analysis (Vol. 11).

Cajaiba-Santana, G. (2014). Social innovation: moving the field forward. A conceptual framework. Technological Forecasting and Social Change, 82(1), 42-51. https://doi.org/10.1016/j. techfore.2013.05.008.

Carsrud, A. L., \& Brännback, M. (2009). Understanding the entrepreneurial mind. New York: Springer.

Chia, C. C., \& Liang, C. (2016). Influence of creativity and social capital on the entrepreneurial intention of tourism students. Journal of Entrepreneurship, Management and Innovation, 12(2), 151-168.

Council of Europe. European Sports Charter (1992). Luxembourg: Office for Official Publications of the European Communities. Retrieved from https://rm.coe.int/16804c9dbb. Accessed 1 May 2019.

Craig, C. L., Marshall, A. L., Sjöström, M., Bauman, A. E., Booth, M. L., Ainsworth, B. E., et al. (2003). International physical activity questionnaire: 12-country reliability and validity. Medicine and Science in Sports and Exercise, 35(8), 1381-1395.

Dawson, P., \& Daniel, L. (2010a). Understanding social innovation: a provisional framework. International Journal of Technology Management, 51(1), 9-21.

Dawson, P., \& Daniel, L. (2010b). Understanding social innovation: a provisional framework. International Journal of Technology Management, 51(1), 456-460. https://doi.org/10.1007/BF02770103.

Díaz-Casero, J. C., Hernández-Mogollón, R., \& Roldán, J. L. (2012). A structural model of the antecedents to entrepreneurial capacity. International Small Business Journal, 30(8), 850-872.

Díaz-García, M. C., \& Jiménez-Moreno, J. (2010). Entrepreneurial intention: the role of gender. International Entrepreneurship and Management Journal, 6(3), 261-283.

Douglas, E. J. (2013). Reconstructing entrepreneurial intentions to identify predisposition for growth. Journal of Business Venturing, 28(5), 633-651.

Eichler, G. M., \& Schwarz, E. J. (2019). What sustainable development goals do social innovations address? A systematic review and content analysis of social innovation literature. Sustainability (Switzerland), 11(2). https://doi.org/10.3390/su11020522.

Eigenschenk, B., Thomann, A., McClure, M., Davies, L., Gregory, M., Dettweiler, U., \& Inglés, E. (2019). Benefits of outdoor sports for society. A systematic literature review and reflections on evidence. International Journal of Environmental Research and Public Health, 16(6), 937.

Fayolle, A., \& Liñán, F. (2014). The future of research on entrepreneurial intentions. Journal of Business Research, 67(5), 663-666.

Ferreira, M. P., Santos, J. C., \& Serra, F. R. (2010). Ser empreendedor: pensar, criar e moldar a nova empresa. Lisboa: Edições Sílabo.

Fisher, R. A. (1950). Statistical methods for research workers (11th ed.). Edinburgh \& London: Oliver and Boyd.

Fragoso, R., Rocha-Junior, W., \& Xavier, A. (2019). Determinant factors of entrepreneurial intention among university students in Brazil and Portugal. Journal of Small Business and Entrepreneurship, 1-25.

Galvão, A., Mascarenhas, C., Rodrigues, R. G., Marques, C. S., \& Leal, C. (2017). A quadruple helix model of entrepreneurship, innovation and stages of economic development. Review of International Business and Strategy, 27(2), 261-282.

Galvão, A., Marques, C. S., \& Ferreira, J. (2019). Evaluation of an entrepreneurship training programme: a proposal for new guidelines. Education+ Training, 61(2), 136-152.

González-Serrano, M. H., Valantine, I., Hervás, J. C., Pérez-Campos, C., \& Moreno, F. C. (2018). Sports university education and entrepreneurial intentions: a comparison between Spain and Lithuania. Education+ Training, 60(5), 389-405. 
Grindell, C., Mawson, S., Gerrish, K., Parker, S., \& Bissell, P. (2019). Exploring the acceptability and usability of a novel social innovation to encourage physical activity: the iStep prototype. Health \& Social Care in the Community, 27(2), 383-391. https://doi.org/10.1111/hsc.12656.

Guerrero, M., Rialp, J., \& Urbano, D. (2008). The impact of desirability and feasibility on entrepreneurial intentions: a structural equation model. International Entrepreneurship and Management Journal, 4(1), 35-50.

Gupta, V. K., Turban, D. B., Wasti, S. A., \& Sikdar, A. (2009). The role of gender stereotypes in perceptions of entrepreneurs and intentions to become an entrepreneur. Entrepreneurship Theory and Practice, 33(2), $397-417$.

Holt, N. L., Kingsley, B. C., Tink, L. N., \& Scherer, J. (2011). Benefits and challenges associated with sport participation by children and parents from low-income families. Psychology of Sport and Exercise, 12(5), 490-499.

Jones, G. J., Carlton, T., Hyun, M., Kanters, M., \& Bocarro, J. (2019). Assessing the contribution of informal sport to leisure-time physical activity: a new perspective on social innovation. Managing Sport and Leisure, 1-14. https://doi.org/10.1080/23750472.2019.1620627.

Krueger, N. F., Jr., Reilly, M. D., \& Carsrud, A. L. (2000). Competing models of entrepreneurial intentions. Journal of Business Venturing, 15(5-6), 411-432.

Landström, H. (2008). Entrepreneurship research: a missing link in our understanding of the knowledge economy. Journal of Intellectual Capital, 9(2), 301-322.4.

Levene, H. (1960). Robust tests for equality of variances. In I. Olkin et al. (Eds.), Contributions to probability and statistics: Essays in honor of Harold Hotelling (pp. 278-292). Stanford: Stanford University Press.

Likert, R. (1932). A technique for the measurement of attitudes. Archives of Psychology, 22(140), 1-55 Available at: http://psycnet.apa.org/psycinfo/1933-01885-001. Accessed 18 June 2019.

Liñán, F., \& Chen, Y. W. (2009). Development and cross-cultural application of a specific instrument to measure entrepreneurial intentions. Entrepreneurship Theory and Practice, 33(3), 593-617.

Liñán, F., \& Fayolle, A. (2015). A systematic literature review on entrepreneurial intentions: citation, thematic analyses, and research agenda. International Entrepreneurship and Management Journal, 11(4), 907-933.

Liñán, F., Moriano, J. A., \& Jaén, I. (2016). Individualism and entrepreneurship: Does the pattern depend on the social context? International Small Business Journal, 34(6), 760-776.

López-Delgado, P., Iglesias-Sánchez, P. P., \& Jambrino-Maldonado, C. (2019). Gender and university degree: A new analysis of entrepreneurial intention. Education+ Training. https://doi.org/10.1108/ET-04-2018-0085.

Lubberink, R., Blok, V., van Ophem, J., \& Omta, O. (2019). Responsible innovation by social entrepreneurs: an exploratory study of values integration in innovations. Journal of Responsible Innovation, 6(2), 179210. https://doi.org/10.1080/23299460.2019.1572374.

Marques, C. S., Ferreira, J., Rodrigues, R. G., \& Ferreira, M. (2011a). The contribution of yoga to the entrepreneurial potential of university students: a SEM approach. International Entrepreneurship and Management Journal, 7(2), 255-278.

Marques, C. S., Santos, G., Gerry, C., \& Gomes, G. (2011b). Business motivation and work-family balance among urban and rural women entrepreneurs in Portugal. Entrepreneurship: Motivation, performance and risk/reward. Nova, Hauppage.

Marques, C. S., Ferreira, J. J., Gomes, D. N., \& Gouveia Rodrigues, R. (2012). Entrepreneurship education: how psychological, demographic and behavioural factors predict the entrepreneurial intention. Education+ Training, 54(8/9), 657-672.

Marques, P., Morgan, K., \& Richardson, R. (2018). Social innovation in question: the theoretical and practical implications of a contested concept. Environment and Planning C: Politics and Space, 36(3), 496-512.

Metsios, G. S., \& Kitas, G. D. (2018). Physical activity, exercise and rheumatoid arthritis: effectiveness, mechanisms and implementation. Best Practice \& Research. Clinical Rheumatology, 32(5), 669-682. https://doi.org/10.1016/j.berh.2019.03.013.

Mulgan, G. (2006). The process of social innovation. Innovations: Technology, Governance, Globalization, 1(2), 145-162 Retrieved from http://www.mitpressjournals.org/doi/10.1162/itgg.2006.1.2.145.

Naia, A., Baptista, R., Biscaia, R., Januário, C., \& Trigo, V. (2017). Entrepreneurial intentions of sport sciences students and theory of planned behavior. Motriz: Revista de Educação Física, 23(1), 14-21.

Onsongo, E. (2019). Institutional entrepreneurship and social innovation at the base of the pyramid: the case of M-Pesa in Kenya. Industry and Innovation, 26(4), 369-390. https://doi.org/10.1080 /13662716.2017.1409104.

Phillips, W., Lee, H., Ghobadian, A., O’Regan, N., \& James, P. (2015). Social innovation and social entrepreneurship: a systematic review. Group and Organization Management, 40(3), 428-461. https://oi.org/10.1177/1059601114560063. 
Pol, E., \& Ville, S. (2009). Social innovation: Buzz word or enduring term? The Journal of Socio-Economics, 38(6), 878-885.

Rao-Nicholson, R., Vorley, T., \& Khan, Z. (2017). Social innovation in emerging economies: a national systems of innovation based approach. Technological Forecasting and Social Change, 121, 228-237. https://doi.org/10.1016/j.techfore.2017.03.013.

Rueda, S., Moriano, J. A., \& Liñán, F. (2015). Validating a theory of planned behavior questionnaire to measure entrepreneurial intentions. In Developing, shaping and growing entrepreneurship (pp. 60-78).

Schlaegel, C., \& Koenig, M. (2014). Determinants of entrepreneurial intent: a meta-analytic test and integration of competing models. Entrepreneurship Theory and Practice, 38(2), 291-332.

Shapero, A., \& Sokol, L. (1982). The social dimensions of entrepreneurship. Encyclopedia of Entrepreneurship, 72-90.

Shinnar, R. S., Giacomin, O., \& Janssen, F. (2012). Entrepreneurial perceptions and intentions: the role of gender and culture. Entrepreneurship Theory and Practice, 36(3), 465-493.

Shook, C. L., Priem, R. L., \& McGee, J. E. (2003). Venture creation and the enterprising individual: a review and synthesis. Journal of Management, 29(3), 379-399.

Thornton, P. H., Ribeiro-Soriano, D., \& Urbano, D. (2011). Socio-cultural factors and entrepreneurial activity: an overview. International Small Business Journal, 29(2), 105-118.

Tukey, J. W. (1949). Comparing individual means in the analysis of variance. International Biometric Society, 5(2), 99-114.

van der Have, R. P., \& Rubalcaba, L. (2016). Social innovation research: an emerging area of innovation studies? Research Policy, 45(9), 1923-1935. https://doi.org/10.1016/j.respol.2016.06.010.

Vassiliou, A. (2014). Foreword in Sport: Linking Education, Training and Employment in Europe: An EOSE Network Perspective.

Westhead, P., \& Wright, M. (2013). Entrepreneurship: A very short introduction. OUP Oxford.

Wilson, F., Kickul, J., \& Marlino, D. (2007). Gender, entrepreneurial self-efficacy, and entrepreneurial career intentions: implications for entrepreneurship education. Entrepreneurship Theory and Practice, 31(3), 387-406.

Yates, F. (1934). The analysis of multiple classifications with unequal numbers in the different classes. Journal of the American Statistical Association, 29(185), 51-66.

Zhao, H., Seibert, S. E., \& Hills, G. E. (2005). The mediating role of self-efficacy in the development of entrepreneurial intentions. Journal of Applied Psychology, 90(6), 1265-1272.

Publisher's note Springer Nature remains neutral with regard to jurisdictional claims in published maps and institutional affiliations.

\section{Affiliations}

\section{Ricardo Rodrigues ${ }^{1,2}$. Carla Susana Marques ${ }^{3}$ - Dulce Esteves ${ }^{1,4} \cdot$ Rui Brás ${ }^{1,4}$. Gina Santos $^{3}$ - Ana Gouveia ${ }^{1,5}$ - Paulo Duarte ${ }^{1,2}$ - Paulo Pinheiro ${ }^{1,2}$. Kelly $\mathrm{O}^{\prime} \mathrm{Hara}^{1} \cdot$ Vanessa Marques $^{3}$}

1 Universidade da Beira Interior, Convento de Santo António, 6200-001 Covilhã, Portugal

2 NECE -UBI -Research Center for Business Sciences, 6200-001 Covilhã, Portugal

3 CETRAD Unit Research and UTAD, Quinta de Prados, DESG-ECHS, Edificio 2, 5000-801 Vila Real, Portugal

4 CIDESD (Sports Sciences, Health Sciences and Human Development), Convento de Santo António, 6200-001 Covilhã, Portugal

5 Instituto de Biofísica e Engenharia Biomédica, Faculdade de Ciências, Universidade de Lisboa, 1749-016 Lisbon, Portugal 